\title{
THE NOVEMBER MEETING IN CLAREMONT
}

The five hundred fiftieth meeting of the American Mathematical Society was held at Pomona College in Claremont, California on Friday and Saturday, November 21 and 22, 1958. There were 171 registrants at this meeting, 139 of whom were members of the Society.

By invitation of the Committee to Select Hour Speakers for Far Western Sectional Meetings, a Symposium on Asymptotic Expansions was held on Friday. The program committee for this symposium consisted of Professors Arthur Erdélyi, chairman, J. G. van der Corput, R. E. Langer, and T. E. Hull. Professor Erdélyi presided over the morning session of the symposium, which was devoted to one hour addresses by Professor van der Corput, University of California at Berkeley, on The theory of neutrices, and by Professor Langer, University of Wisconsin, on Asymptotic solutions of ordinary linear differential equations with respect to a parameter. Shorter talks were given in two afternoon sessions, presided over by Professor S. E. Warschawski, University of Minnesota and Professor M. R. Hestenes, University of California at Los Angeles. The following addresses were given at these sessions: On integral equations with asymptotic Liouville Neumann series, Professor T. E. Hull, University of British Columbia and California Institute of Technology; Saddle-point integrals with neighboring saddle points, Professor B. Friedman, University of California at Berkeley; Recent advances and open questions on the asymptotic expansions of orthogonal polynomials, Professor G. Szegö, Stanford University; The asymptotic behavior of the Laurent coefficients, Professor Max Wyman, University of Alberta; Simplification of systems of linear differential equations involving a turning point, Professor H. L. Turrittin, University of Minnesota; Linear differential equations of the second order with a large parameter, Mr. F. W. J. Oliver, National Physical Laboratory (England) and National Bureau of Standards.

By invitation of the Committee to Select Hour Speakers for Far Western Sectional Meetings, Professor Leon Henkin of the University of California at Berkeley addressed the Society Saturday afternoon on Some recent work on real closed fields. He was introduced by Professor Alfred Tarski of the University of California at Berkeley.

There were three sessions for contributed papers on Saturday with Professors R. L. Vaught, Chester Jaeger and Hans Zassenhaus presiding. Mr. Ehrenfeucht was introduced by Professor Vaught and Mr. H. J. Keisler by Dr. Olga Taussky Todd.

\section{R. S. Pierce Acting Associate Secretary}

